\section{DUODENAL ULCER}

\section{DR. A. W. ALLEN'S MOYNIHAN LECTURE}

At the Royal College of Surgeons on Sept. 22, as was briefly reported last week (p. 505), Dr. Arthur W. Allen, of Harvard, President of the American College of Surgeons, delivered the Moynihan Lecture, taking as his subject "Duodenal Ulcer."

Dr. Allen began by saying he had not chosen duodenal ulcer as a subject because of the pioneer work done by Moynihan, in whose memory the lecture was founded, for Moynihan, though he carried out important work in this field, had many other interests. He had chosen it because the subject was still in $a^{2}$ fluid state. Ideas were constantly changing. No sooner did there seem to be an answer, or a probable answer, to some problem than doubt arose owing to the appearance of apparently contradictory results. Perhaps $10 \%$ of patients failed to get along under conservative treatment and came into the hands of surgeons who, after years of trial and error, thought that they had hit upon the solution in subtotal gastric resection. Although it was obvious that this operation was giving a high proporticn of good results-a higher proportion than any other method heret of ore ad- vanced-he himself began to have misgivings a few years ago. Some patients were not improved after the procedure, and there were a few who sèmed to have been made worse. In an analysis of the gastrectomies he had carried out for uncomplicated duodenal ulcer it was obvious that a certain number of the patients had side effects which were perhaps worse than their original malady. Physiologists were continually looking for an explanation of this wayward situation arising in one patient when the previous nine and the following nine had no trouble whatever, and they had turned to the question of hyper-secretion and hyper-acidity, without which ulcer of the duodenum did not occur.

In Dr. Phemister's clinic in Chicago, Dragstedt had brought forward the possibility of treatment of duodenal ulcer by interruption of the vagus nerve. He (Dr. Allen) had a group of his own patients who had been treated by subtotal gastrectomy and had been the subject of a follow-up extending over ten years. In his hospital there was also a group of patients who had been treated by vagus resection with a follow-up extending, however, over a much shorter period (about four years). It was his intention to show comparatively the results obtained in these two groups.

\section{Subtotal Gastrectomy}

In the first place Dr. Allen with the aid of diagrams described the operation of subtotal gastrectomy for duodenal ulcer, with certain modifications to meet particular types of cases. The first procedure, which had been followed in the great majority of his own cases, was primary resection with removal of the ulcer-bearing portion of the duodenum. The second was one which he had found useful on occasion for any deep-lying ulcer with adhesions; it was followed in cases in which there was a sufficient amount of free duodenum above the ulcer so that the resection could be done, the ulcer excluded, and nothing left which might produce a recurrence. A third possibility related to patients with very extensive ulceration or adhesions, who might perhaps have had a perforation previously, and on whom it was necessary to operate for mechanical reasons. Here a procedure was resorted to whereby the antrum was cut, the mucosa of the antral segment carefully removed, and the segment turned in. The fourth type of procedure was adopted in certain difficult cases when a two-stage operation seemed to be justifiable. Gastrectomy for exclusion was done, but no attempt was made at the time to remove the antral mucosa. Six weeks later, however, another operation was done on the patient for this purpose. The idea was that this made the operation a safe one for the general surgeon who was not carrying out gastric surgery regularly, and that the safeguard of a two-stage operation would mean a lower mortality and fewer complications. This operation had been undertaken quite extensively at the Massachusetts General Hcspital, but he had seldom found it necessary in his own practice.

An analysis of his 196 consecutive operations on patients with uncomplicated duodenal ulcer, carried out according to the four procedures set out above, is given in the table below.

The mortality was mostly due to difficulty with the duodenal stump, because resection had to be done so low that there was no room to get an adequate turn-up. He had excluded from this list, in order to get a true comparison with vagus resection, those cases which had previously been the subject of unsuccessfurl s u rgery and those in the acute stage of massive haemorrhage. On the matter of age, even elderly patients who were bleeding from a ulcer, if operated on immeciately they got over the shock, would show a very low mortality. Actually in twelve patients who were over 65 there was only one death. But, of course, it was a question how much should be ascribed to the particular procedure followed and how much to the generally heightened level of surgery. Surgery in every field was far safer than it was ten years ago. Mortality rates were coming down, and death after operation in the modern hospital was now a rarity.

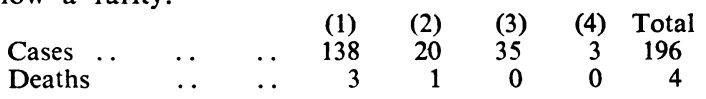

\section{Vagus Resection}

Dr. Allen prcceeded to show further diagrams illustrating how the section of the vagus should and should not be done. A possible error was inadequate removal of the nerve. The procedure which should be followed was the removal of a long segment, not less than $5 \mathrm{~cm}$., preferably $10 \mathrm{~cm}$., of the vagus nerve, and the encapsulation of the upper end in an impermeable cylinder in the hope that this might delay regeneration. All the cases at his own hospital had been operated on in 
that way. They did not complicate their cases with gastroentercstomies. They had not carried out this operation for gastric ulcer for the very obvious reason that they were not able to determine whether the ulcer was benign; $14 \%$ of the cases diagnosed as benign ulcer of the stomach proved to be cancerous. Therefore vagus resection had no place in the surgery of gastric ulcer.

The statistics from his hospital for vagus resections carried out from 1944 to 1947 were as follows :

\begin{tabular}{lllcc} 
& & \multicolumn{2}{c}{ Number of Cases } & Deaths \\
Duodenal ulcer & $\ldots$ & $\ldots$ & 75 & 0 \\
Jejunal uicer & $\ldots$ & $\ldots$ & 22 & 0 \\
Miscellaneous &. & $\ldots$ & 6 & 1
\end{tabular}

The 75 cases were of uncomplicated duodenal ulcer. The patients had undergone various forms of medical treatment. Most of them had been through the hands of the psychiatrist. Finally, when it became obvious that nothing could be done by those means, they were chosen for this surgical procedure because they had no obstruction at the outlet of the stomach or in the duodenum, and most of them were young. Twentytwo cases were operated on for anastomotic ulcer. These were the type of cases in which the procedure he had indicated had its most spectacular effect. This group of anastomotic ulcers could be relieved certainly temporari'y by this method, and it was startling to see them wakened from anaesthesia free from pain for the first time for months. He added that the nerves should be injected with novocain before they were severed or manipulated, and the patients should receive large doses of atropine. He showed a radiograph illustrating the appearance twelve days after resection in a case in which there had been a good-sized jejunal ulcer, and many such results could be shown. There had been almost no trouble from empyema and complications of that kind. He also showed a curve illustrating the effect which the vogue of vagus resection had had upon the number of private patients coming to him and being treated by subtotal gastrectomy. The curve showed a certain fall during the years in which vagus resection had come into favour, but he added that they were not quite so enthusiastic now about vagus resection as they were at the beginning.

\section{The Methods Compared}

Dr. Allen next showed the result of a follow-up extending back for ten years in the cases of subtotal gastrectomy and four years in the cases of vagus resection.

\begin{tabular}{|c|c|c|c|c|c|}
\hline \multirow{2}{*}{\multicolumn{2}{|c|}{ Number of cases }} & & \multicolumn{2}{|c|}{$\begin{array}{c}\text { Subtotal } \\
\text { Gastrectomy }\end{array}$} & $\begin{array}{c}\text { Vagus } \\
\text { Resection }\end{array}$ \\
\hline & & $\cdots$ & . & 196 & 75 \\
\hline Average age & $\ldots$ & . & . & 47.4 & 42.1 \\
\hline Males & .. & . & . & $84 \%$ & $84 \%$ \\
\hline Recurrent ulcer & .. & $\ldots$ & . & $34 \%$ & $14 \%$ \\
\hline Good result & . & $\cdots$ & $\cdots$ & $85 \%$ & $87 \%$ \\
\hline Fair result. & .. & . & . & $7 \%$ & $6 \%$ \\
\hline Poor result & $\cdots$ & $\cdots$ & $\cdots$ & $8 \%$ & $7 \%$ \\
\hline Operative morta & lity & . . & . & $2 \%$ & $\mathrm{Ni!}$ \\
\hline
\end{tabular}

These were all cases of primary duodenal ulcer. In his own group of subtotal gastrectomies he was ready to claim that $85 \%$ showed satisfactory results. Many of the patients had to be questioned very closely to get much in the way of symptoms out of them. The results described as "fair" were those in which the patient was not quite well, was subject to restrictions in diet, and, if not actually showing loss of weight, had to be the subject of considerable attention in order to maintain weight.

The drawbacks attaching to subtotal gastrectomy for duodenal ulcer were a certain though very small operative mortality, a number of cases of anastomotic ulcer, a few cases of gastritis with bleeding, the exhibition occasionally of the "dumping syndrome" (in which there were distress, sweating, and sometimes nausea after eating-but most patients got over it), a certain amount of weight loss which was a problem with some of the older patients, and a gastro-intestinal reflex indicated by loose stools and the like.

Vagus resection had also the drawback of occasional recurrent ulcers. It was hard to say after what period recurrences were no longer to be expected. In his hospital, for example, one-third of the anastomotic ulcers which followed operation occurred within the first year, another third within the second year, but the remaining third were spread over a period of many years. Therefore it was difficult to use the term "end result," and perhaps it should never be used in a situation of this kind. Two of the patients who had undergone vagus resection had persistent ulcer pain after the operation as well as before it; some had pain and bleeding; others had a feeling of distension; eructations were almost the rule, though this was usually transient, and diarrhoea and slight obstruction were not infrequent.

\section{Conclusions}

This entire problem should be viewed with an open mind. Vagus resection was a useful procedure and might have a permanent place in the treatment of duodenal ulcer. But unless the results were critically analysed, not only of vagus resection but of subtotal gastrectomy, their colleagues who had not the opportunity of following up a group of cases over a sufficient period would be misled. Either an adequate subtotal gastrectomy or vagus resection would give a high incidence of immediate relief in intractable duodenal ulcer. Vagus resection was the procedure of choice in anastomotic ulcer following upon subtotal gastrectomy. It was also to be recommended in intractable duodenal ulcer in younger patients. Vagus resection had no place in the treatment of gastric ulcer on account of the difficulty of distinguishing benign from malignant ulceration of the stomach, and because of the excellent results and low mortality obtained by gastric resection in gastric ulcer. In vagus resection the transthoracic approach was the most adaptable for an interruption of the efferent pathway. Obviously many years of experience and careful selection of patients and adequate follow-up would be necessary properly to evaluate vagus resection. Subtotal gastrectomy was, in his opinion, to be preferred for all patients who had superficial obstruction from duodenal ulcer, for those with acute massive bleeding when any operation was indicated, and for those with intractable ulcer in the later age groups.

(See also an annotation on this subject at p. 538.)

\section{INTERNATIONAL SOCIETY OF SURGERY \\ VISIT TO EDINBURGH}

Following the Twelfth Congress of the International Society of Surgery in London, about 160 members of the Society visited Edinburgh from Sept. 23 to 26 . A comprehensive and detailed programme arranged by the Department of Surgery of the University of Edinburgh included a wide choice of operating sessions at many of the voluntary and municipal hospitals in the city, and special demonstrations at the University departments of surgery and anatomy. The library and museum of the Royal College of Surgeons of Edinburgh were also open to members of the Society throughout their visit. On Tuesday morning Prof. J. R. Learmonth extended a cordial welcome to the visitors. Later a number of members were present as guests of His Majesty's Government at lunch in the Caledonian Hotel, under the chairmanship of the Rt. Hon. Joseph Westwood, M.P., Secretary of State for Scotland. In the afternoon the scientific sessions began.

\section{Treatment of Thyrotoxicosis}

Prof. D. M. Dunlop presented a study of 76 consecutive cases of thyrotoxicosis treated with thiouracil over periods varying from one to three and a half years. The initial dosage was $0.6 \mathrm{~g}$. daily, for three to four weeks, followed by maintenance doses of 0.05 to $0.2 \mathrm{~g}$. daily. Overdosage caused myxoedema and increase in the size of the goitre. The results in 66 of the cases were comparable to those following successful thyroidectomy. Drug resistance was encountered in 4 cases and required thyroidectomy, which was also performed with good results in 5 out of 6 cases showing toxic reactions to the drug. Of 43 patients in whom treatment was stopped after about a year, 13 had remained free of symptoms for one to three years. The other 30 had relapsed at varying periods after stopping the 